\title{
Effect of Adhesion Booster on Fluoride-releasing Composite: An in vitro Study
}

\author{
Dr Varunjeet Chaudhary, Dr Sanad Singh Solanki, ${ }^{2}$ Dr Varsha Yadav, ${ }^{3}$ Dr Seema Lahoti ${ }^{4}$ \\ 'Senior Lecturer, 2 PG Resident, ${ }^{3}$ Tutor, ${ }^{4 R e a d e r}$, Dept of Orthodontics \\ RKDF Dental College, Bhopal, India
}

Correspondence: Dr Varunjeet Chaudhary; Email: drvarunjeetchaudhary@gmail.com

\section{ABSTRACT}

Objective: To evaluate the shear bond strength of stainless steel brackets bonded with fluoride-releasing composite resins, comparing effect of adhesion booster and conventional primer.

Materials \& Method: Sixty extracted premolars were subjected to bracket bonding with fluoride-releasing composite resin; which were bonded by randomly divided into two groups of bonding agents: Group 1- conventional primer as control group, Group 2- adhesion booster. After bonding, the samples were thermocycled $(500 \mathrm{cycles})$ at $5^{\circ} \mathrm{C}$ and $55^{\circ} \mathrm{C}$ temperatures. After 48 hours they were subjected to shear bond strength testing in occluso-gingival direction, using an MTS 810 Universal Testing Machine with load speed of $0.5 \mathrm{~mm} / \mathrm{min}$.

Result: Mean shear bond strength was significantly more in samples bonded with adhesion booster (14.792 $\pm 3.805 \mathrm{Mpa})$ as compared to conventional primers (11.327 $\pm 4.047 \mathrm{Mpa})$. There was statistically significant difference in shear bond strength between the groups $(p=0.001)$.

Conclusion: The use of the adhesion booster significantly increased the bond strength of bracket bonded with fluoride-releasing composite.

Key-words: brackets, composite resin, shear bond strength

\section{INTRODUCTION}

Fixed orthodontic appliances predispose to the accumulation of plaque around the brackets and make it difficult to maintain the oral hygiene of a patient. The decalcification of enamel surface adjacent to the orthodontic bracket is a common problem during orthodontic treatment.' Therefore many methods are being tried to reduce the risk of demineralization, which can be done by performing plaque control and fluoride application methods. ${ }^{2,3}$ However it has been found that the use of fluoride toothpaste did not prevent the risk of enamel decalcification around the brackets because it purely depends upon the dietary habits and daily routine followed by the patient. ${ }^{4}$

Topical fluoride application reduces the bond strength and the fluoridated elastomeric ligatures are not effective in reducing the decalcification.5.6 Recently various advancements have been done in orthodontic adhesives for example: glass ionomer resins with continuous sustained release of fluoride at the bracket enamel interface resulting in the reduction of caries. ${ }^{7-9}$ Low bond strength associated with glass ionomer resins restrict their use in orthodontics to band cementation only. ${ }^{10-13}$

Addition of inorganic fluorides into composite resin causes problems like phase separation and loss of mechanical integrity of the resin. The reason behind is highly polar nature of fluoride salts and low polarity of the resins. Organic fluoride incorporation has a plasticizing effect that also results in poor properties. ${ }^{8}$

There have been many strategies to decrease the bond failure, such as: (1) adhesive materials, (2) innovative bracket base designs, (3) enamel etching procedures and (4) sandblasting techniques. A relatively new method to enhance the bond strength of orthodontic brackets is the use of adhesion boosters which was developed to reduce the bond failure rate. They incorporate hydrophilic monomers and other adhesion enhancers into the primer. ${ }^{14}$ The addition of hydrophilic monomers to adhesive systems facilitates resin infiltration into the etched enamel; this reduces the interfacial porosity and adhesive defects, hence resulting in better bond strength after polymerization. ${ }^{15}$ 
The present study compared the effect of two different primers on bond strength; namely Group 1- conventional primer (Rely-a-Bond) as control group and Group 2adhesion booster (Assure, Reliance) along with fluoridereleasing composite resins.

\section{MATERIALS AND METHOD}

The study was carried at the Dept of Orthodontics, RKDF Dental College after receiving ethical approval. Sixty extracted human premolars with intact buccal enamel without any hypoplastic spots, extracted for orthodontic treatment purpose were collected. These teeth were stored in distilled water which was changed periodically every 2 weeks until bonding was conducted. The material used for bonding was fluoride-releasing composite (Figure 1) using $37 \%$ Orthophosphoric acid (Figure 2).

The specimens were randomly divided into two equal groups for bonding:

Group 1: Brackets bonded with 'Rely-a-bond' conventional primer ( $n=30)$ (Figure 3)

Group 2: Brackets bonded with 'Assure' adhesion booster $(n=30)$ (Figure 4)
In both the groups same fluoride-releasing composite was applied. Standard bonding protocol was followed. Immediately after bonding, the teeth were stored in distilled water at room temperature for 24 hours; next, thermocycling was performed for 500 cycles at $5^{\circ} \mathrm{C}$ and $55^{\circ} \mathrm{C}$ (Figure 5). After this, the specimens underwent shear bond strength tests (Figure 6). A mechanical Universal Testing Machine with a 1-kN load and at a speed of 0.5 $\mathrm{mm} / \mathrm{min}$ was used to determine the maximum shear strength required to debond the brackets. The specimens were placed in the machine so that the chisel was as close as possible to the tooth/bracket base interface, allowing the force to be applied parallel to the bracket base. The force was recorded in Newton for each specimen and divided by the area of the bracket base to estimate the shear bond strength in megapascals (MPa).

The data were subjected to statistical analysis to determine the most effective material on shear bond strength. Descriptive statistics with mean and standard deviation were calculated and Student's t-test were performed to find the statistical difference between the groups.

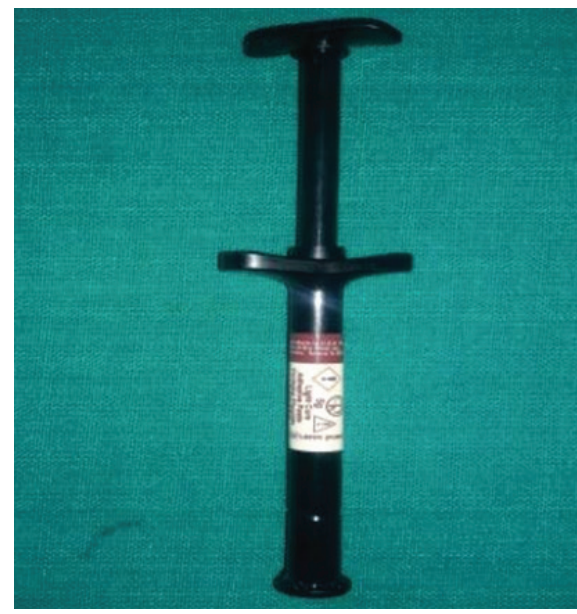

Figure 1: Composit resin with fluoride

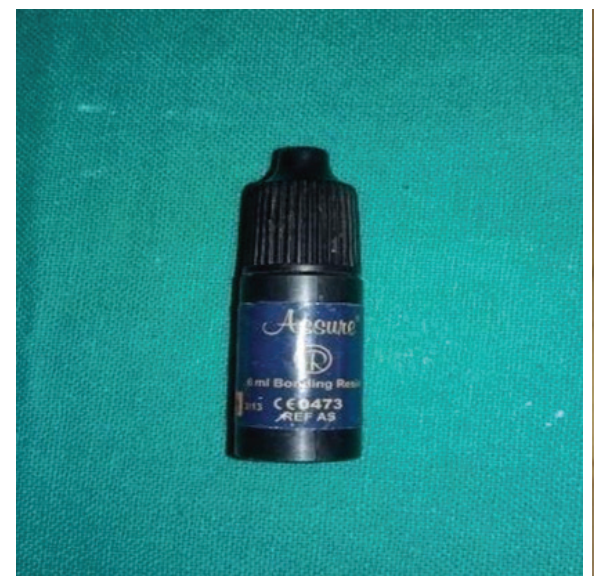

Figure 4: Adhesion booster

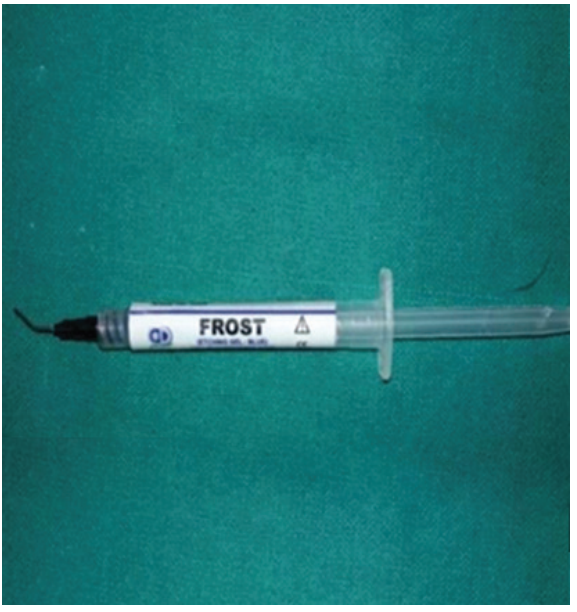

Figure 2: $37 \%$ Orthophosphoric acid

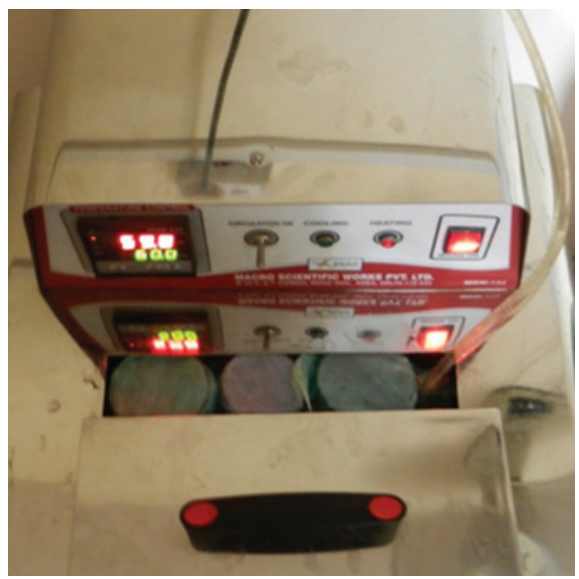

Figure 5: Thermocycling unit

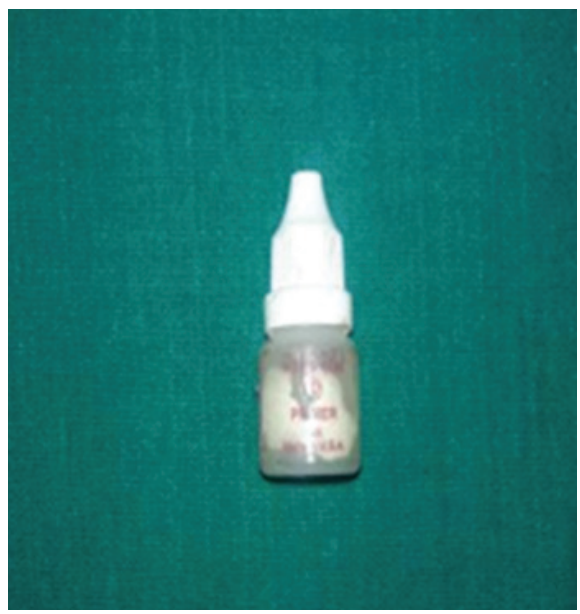

Figure 3: Conventional primer

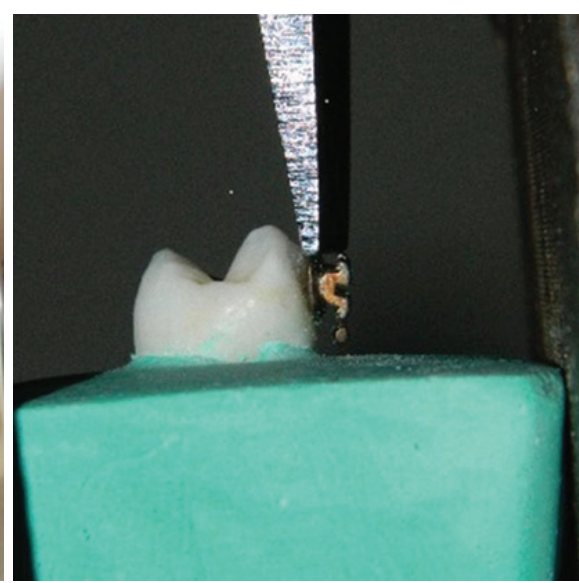

Figure 6: Bracket debonding in Universal Testing Machine 
Table 1: Comparison of shear bond strength between two groups

\begin{tabular}{|c|c|c|c|c|c|c|}
\hline \multirow{2}{*}{ Group } & \multirow{2}{*}{$\mathbf{N}$} & \multicolumn{3}{|c|}{ Shear Bond Strength (MPa) } & \multirow{2}{*}{ t-Value } & \multirow{2}{*}{$p$-Value } \\
\hline & & Mean & SD & Range & & \\
\hline Group 1 & 30 & 11.327 & 4.047 & $5.10-18.20$ & \multirow{2}{*}{3.944} & \multirow{2}{*}{$0.001^{*}$} \\
\hline Group 2 & 30 & 14.792 & 3.805 & $8.40-20.90$ & & \\
\hline
\end{tabular}

*Significant at $p<0.01$

\section{RESULT}

The mean shear bond strength was significantly higher in samples bonded with Assure adhesion booster (Group 2) as compared to samples bonded with Rely-a-bond conventional primer (Group 1). It was 14.792 \pm 3.805 Mpa for

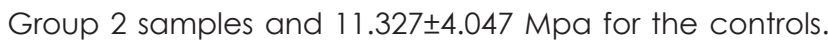
There was statistically significant difference in shear bond strength between the groups $(p=0.001)$ (Table 1).

\section{DISCUSSION}

It has been seen that demineralization of enamel during orthodontic treatment can occur within 4 weeks of treatment. ${ }^{16,17}$ So for this we used fluoride-relaesing composite resin which reduce decalcification of the brackets. ${ }^{10,11}$ Addition of fluoride in the composite resin affects the bond strength. . $^{8} 18$

Reynolds and Greenlaw et al have suggested that bond strengths of 5.9-9.7 MPa are appropriate for clinical treatment in orthodontics. ${ }^{19,20}$ However, the minimum in vitro bond strength required for reliable orthodontic bonding remains unknown. The mean bond strength obtained in vitro in the two group in this study ranged from 11.33-14.79 MPa, values that would be appropriate for orthodontic treatment according to several authors. 19,20

A study was conducted by Egan et al using human premolars to evaluate the efficacy of Enhance adhesion booster when used together with a conditioner that contained methyl methacrylate (Plastic Conditioner, Reliance Products Inc.) for direct bracket bonding. They concluded that the use of those products did not increase the bond strength of rebonded brackets. ${ }^{21}$ In the present study, when adhesion booster was used there was a significant increase in shear bond strength.

Another study conducted by Schaneveldt and Nemeth et al in which they have evaluated the effect of adhesion booster on direct bracket bonding in cases of saliva or blood contamination and found that Assure bonding resin produced adequate bond strength under dry and humid conditions. ${ }^{22,23}$ The present study was done using fluoride containing composite under dry conditions and the results of the study indicated that the adhesion booster is capable of increasing the shear bond strength .

O'Brien et al found that the location of bond failure is affected by the type of adhesive material used. ${ }^{24}$ Adhesion booster is a hydrophilic primer composed of biphenyl dimethacrylate and hydroxyethyl methacrylate, which is indicated to increase adhesion to enamel, dentin, metal, and resin surfaces. In the present study conventional primer did not receive any booster in bonding while adhesion booster received universal bonding resin. Shear bond strength was found highest in adhesion booster.

Several factors may affect bracket bonding in patients. These factors are difficult to reproduce in the laboratory, and this in vitro study therefore cannot be understood as a comprehensive representation of clinical cases. In the oral cavity, bonded brackets are exposed to variations in humidity and temperature. These variables may lead to stress on the adhesive and on the brackets, which may affect bond strength. ${ }^{25}$ Therefore, thermocycling was used to produce a better simulation of the intraoral conditions.

\section{CONCLUSION}

In vitro shear bond strength was acceptable in both control group bonded with conventional primer and experimental group bonded with adhesion booster (Assure). The use of the adhesion booster significantly increased the bond strength of bracket bonded with fluoride-releasing composite. Hence, the use of adhesion booster in orthodontics can certainly improve the treatment quality and save operator's time in rebonding the bracket. 


\section{REFERENCES}

1. Gwinnet AJ, Ceen RF. Plaque distribution on bonded brackets: A scanning microscope study. Am J Orthod. $1979 ; 75: 667$ 77.

2. Årtun J, Bergland S. Clinical trials with crystal growth conditioning as an alternative to acid-etch enamel pretreatment. Am J Orthod.1984; 85(4):333-40.

3. O'Reilly MM, Featherstone JDB. Demineralization and remineralization around orthodontic appliances: An in vivo study. Am J Orthod Dentofac Orthop. 1987; 92(1):33-40.

4. Øgaard B, Rezk-Lega F, Ruben J, Arends J. Cariostatic effect and fluoride release from a visible light-curing adhesive for bonding of orthodontics brackets. Am J Orthod Dentofac Orthop. 1992; 101 (4):303-7.

5. Sheykholeslam Z, BuonocoreMG, Gwinnett AJ. Effect of fluorides on the bonding of resins to phosphoric acid etched bovine enamel. Arch Oral Biol. 1972; 17:1037 45

6. Benson PE, Douglas CW, Martin MV. Fluoridated elastomers: Effect on the microbiology of plaque. AM J Orthod Dentofac Orthop. 2004 126:325 30.

7. Sonis AL, Snell W. An evaluation of a fluoride releasing, visible light activated bonding system for orthodontic bracket placement Am $\mathrm{J}$ Orthod Dentofac Orthop. 1989; 95:306 11.

8. Underwood ML, Rawls HR, Zimmerman BF. Clinical evaluation of a fluoride exchanging resin as an orthodontic adhesive. Am J Orthod Dentofac Orthop. 1989; $96: 939$.

9. McNeil CJ, Wiltshire WA, Dawes C, Lavelle CL. Fluoride release from new light cured orthodontic bonding agents. Am J Orthod Dentofac Orthop. 2001; 120:392 7 .

10. Lim BS, Lee SJ, Lim YJ, Ahn SJ. Effects of periodic fluoride treatment on fluoride ion release from fresh orthodontic adhesives. J Dent. 201 1 ; $39: 78894$

11. Fox NA. Fluoride release from orthodontic bonding materials. An in vitro study. Br J Orthod. 1990; 17:293 8.

12. Ewoldsen N, Demke RS. A review of orthodontic cements and adhesives. Am J Orthod Dentofac Orthop. 2001; $120: 458$

13. Antonucci JM, MCKinney JE, Stansbury JW. Resin modified glass ionomer cement. US patent application. 1988; 856:7 160.

14. Wenger NA, Deacon S, Harradine NW. A randomized control clinical trial investigating orthodontic bond failure rates when using Orthosolo universal bond enhancer compared to a conventional bonding primer. J Orthod. 2008; 35:27-32.

15. Vicente A, Bravo LA, Romero M, Orti'z AJ, Canteras M. Effects of three adhesion promoters on the shear bond strength of orthodontic brackets: An in-vitro study. Am J Orthod Dentofac Orthop. 2006; 129:390-5.

16. Ogaard B, Rølla G, Arends J. Orthodontic appliances and enamel demineralization. Part 1. Lesion development. Am J Orthod Dentofac Orthop. 1988; $94: 6873$.

17. Summers A, Kao E, Gilmore J, Gunel E, Ngan P. Comparison of bond strength between a conventional resin adhesive and a resin reinforced glass ionomer adhesive: An in vitro and in vivo study. Am J Orthod Dentofac Orthop. 2004; 126:200-6.

18. Newman GV, Newman RA, Sun BI, Jack Ha JL, Ozsoylu SA. Adhesion promoters, their effect on the bond strength of metal brackets. Am J Orthod Dentofac Orthop. 1995; 108:237-41.

19. Reynolds IR. A review of direct orthodontic bonding. Br J Orthod. 1975; 2:171-8.

20. Greenlaw R, Way DC, Galil KA. An in vitro evaluation of a visible light-cured resin as an alternative to conventional resin bonding systems. Am J Orthod Dentofacial Orthop. 1989; 96:214-20.

21. Egan FR, Alexander SA, Cartwright GE. Bond strength of rebonded orthodontic brackets. Am J Orthod Dentofac Orthop. 1996; 109:64-70.

22. Schaneveldt S, Foley TF. Bond strength comparison of moisture-insensitive primers. Am J Orthod Dentofacial Orthop. 2002; 122:267-73.

23. Nemeth BR, Wiltshire WA, Lavelle CL. Shear/peel bond strength of orthodontic attachments to moist and dry enamel. Am J Orthod Dentofac Orthop. 2006; 129:396-401.

24. O'Brien KD, Watts DC, \& Read MJ. Residual debris and bond strength: Is there a relationship? Am J Orthod Dentofac Orthop. 1988; 94(3):222-30.

25. Brauchli L, Zeller M, Wichelhaus A. Shear bond strengths of seven self-etching primers after thermo-cycling. J Orofac Orthop. 201 1; 72:37180.

26. Akhoundi A, Mojtahedzadeh F. Problems in standardization of orthodontic shear bond strength tests; a brief review. J Dent. 2005; 2(1):3640 .

27. Williams VD,Svare CW. The effect of five-year storage prior to bonding on enamel/composite bond strength. J Dent Res.1985; 64(2):151-4.

28. Bishara SE, Vonwald L, Laffoon JF, Warren JJ. The effect of repeated bonding on the shear bond strength of a composite resin orthodontic adhesive. Angle Orthod. 2000; 70(6):435-41.

29. Fernandes TMF, Janson G, Somensi J, Pinzan A, Francisconi PAS, Sathler R, Henriques JFC. Effects of modifying the bonding protocol on the shear bond strength of metallic and ceramic orthodontic brackets. Gen Dent. 2012; 60(1):51-5. 